\section{Case Reports in Ophthalmology}

\title{
Peters Anomaly in Twins: A Case Report of a Rare Incident with Novel Comorbidities
}

\author{
Hashem S. Almarzouki Alaa A. Tayyib ${ }^{b}$ Hassan A. Khayat ${ }^{c}$ \\ Raed E. Alsulami ${ }^{c}$ Saeed M. Alzahrani ${ }^{c} \quad$ Abdulaziz S. Alkahtani ${ }^{c}$ \\ Loai S. Alghifees ${ }^{d}$
}

${ }^{a}$ King Abdullah International Medical Research Center, Department of Ophthalmology, King Abdulaziz Medical City, Ministry of National Guard Health Affairs (MNG-HA), Jeddah, Saudi Arabia; ${ }^{b}$ King Abdullah International Medical Research Center, Department of Ophthalmology, King Abdulaziz University Hospital, Jeddah, Saudi Arabia; 'King Abdullah International Medical Research Center, College of Medicine, King Saud bin Abdulaziz University for Health Sciences, Ministry of National Guard Health Affairs (MNG-HA), Jeddah, Saudi Arabia; ${ }^{d}$ King Abdullah International Medical Research Center, College of Medicine, Umm Al-Qura University, Mecca, Saudi Arabia

\section{Keywords}

Peters anomaly · Genetic basis - Comorbidities - Ocular abnormalities · Systemic malformation · Monozygotic twins

\begin{abstract}
Introduction: Peters anomaly is a rare developmental malformation involving the anterior segment of the eye, which culminates in amblyopia or congenital blindness. Multiple ocular and/or systemic malformations have been observed with this anomaly, and novel comorbidities continue to be reported. Case Presentation: The probands were monozygotic twin boys (twin I and twin II) born to consanguineous parents at 36 weeks of gestation. Coarse facial features and deep-seated eyes were noted at birth. At 6 months, ophthalmic examination revealed that both twins were unable to blink in response to light, or to fixate and follow a moving object. Both twins had prominent horizontal nystagmus. Slit-lamp examination demonstrated varying degrees of central leukoma (corneal opacity) associated with iridocor-
\end{abstract}

\section{KARGER}

Hassan A. Khayat, MBBS

King Abdullah International Medical Research Center

King Saud bin Abdulaziz University for Health Sciences, College of Medicine

Ministry of National Guard Health Affairs (MNG-HA)

King Abdulaziz Medical City (KAMC), Jeddah 21423 (Saudi Arabia)

E-Mail khayyatha@ngha.med.sa 


\section{Case Reports in Ophthalmology}

neal adhesion, which is characteristic of type I Peters anomaly. No cataractous changes were observed. Normal intraocular pressure and disorganized retina were observed. Pupillary abnormalities included bilaterally underdeveloped pupils and bilateral absence of pupils was noted. Ocular MRI showed bilateral microphthalmia and optic nerve hypoplasia, with a small optic chiasm in both twins. At this age, the diagnosis of Peters anomaly was made. At 16 months of age, both twins developed deep venous thrombosis and purpuric skin lesions. Investigations revealed a hereditary thrombophilia secondary to a homozygous mutation causing protein $\mathrm{C}$ deficiency, which is a rare thrombotic condition. Ocular ultrasonography revealed bilateral vitreous hemorrhaging linked to altered coagulation. One twin developed bilateral inguinal hernia and cryptorchidism. Conclusion: The novel concordance of Peters anomaly in these monozygotic twins sharing a mutation in PROC gene provides further evidence that this anomaly has a genetic basis. Hypoplasia of the optic nerves and optic chiasm, along with severe protein $C$ deficiency and bilateral absence of the pupils, are associated comorbidities that have not previously been reported with this anomaly.

(C) 2016 The Author(s)

Published by S. Karger AG, Basel

\section{Introduction}

In 1906, Albert Peters first described the associations between Descemet's membrane defect, a shallow anterior chamber, iridocorneal synechiae (adherences) and corneal leukoma (opacity) [1]. The term Peters anomaly was later coined to describe this syndrome. The spectrum of conditions referred to as Peters anomaly has now expanded to include cases with unilateral or bilateral ocular involvement, with or without systemic associations. In 1974, Townsend et al. [2] proposed a classification system for Peters anomaly that was divided into three types: central corneal leukoma alone, central corneal leukoma with corneolenticular touch, and central corneal leukoma with Rieger's mesodermal dysgenesis. A consensus has now been established for variations on this categorization system: 'type I' features corneal opacity and iridocorneal synechiae, 'type II' is characterized by central corneal opacity and a cataractous lens that may adhere to the cornea, and 'Peters plus' is associated with short stature, developmental delays, and a cleft lip or palate [3].

Being a rare disorder, its exact etiology is yet to be elucidated. However, several previous observations did clearly point to a genetic etiology [4]. In addition, a number of ocular and systemic findings are known to be associated with Peters anomaly, including microphthalmia, cardiac malformations and cleft palate [4]. Other associated conditions are rarely observed, such as Wilms' tumor and corneal perforation [5, 6]. Notably, novel associations are still being described. The current study reports a unique concordance of Peters anomaly in monozygotic twins associated with multiple novel comorbidities.

\section{Objectives}

To report an unusual incidence of Peters anomaly occurring in twins, and featuring many novel findings. 


\section{Case Reports in Ophthalmology}

\begin{tabular}{|l|l|l}
\hline DOI: $10.1159 / 000450571$ & (c) 2016 The Author(s). Published by S. Karger AG, Basel \\
\hline
\end{tabular} www.karger.com/cop

Almarzouki et al.: Peters Anomaly in Twins: A Case Report of a Rare Incident with Novel Comorbidities

\section{Method}

Case study, with data collection through review of the patients' charts, clinical and radiological assessments. Parental informed consent to participate in this study was obtained.

\section{Results}

Twin boys were born to second-degree consanguineous Saudi parents at 36 weeks of gestation by elective Caesarean section. Both parents were asymptomatic carriers for a hereditary thrombophilia as genetic analysis revealed a heterozygous mutation associated with vitamin K-dependent protein C deficiency. Both parents have no eye abnormality. Neonatal examination revealed corneal opacification. At 6 months, the twins were referred to our ophthalmology clinic after the parents noticed rapidly increasing ocular haziness. Ophthalmic examination revealed that the twins did not blink in response to light, could not fixate on and follow a moving object, and had prominent horizontal nystagmus. The eyelids were normal, with no ptosis. Slit-lamp examination identified different degrees of bilateral central leukoma $(2 \times 2 \mathrm{~mm})$ in twin I and $(4 \times 3 \mathrm{~mm})$ in twin II associated with iridocorneal adhesion, which is characteristic of type I Peters anomaly (fig. 1, fig. 2). The periphery of the cornea was not involved with this opacity bilaterally in both children. The corneal opacity was mainly concentrated at the center. Twin I had lenses in the normal position, with no adherence to the posterior cornea and no cataractous changes. He had abnormal, disorganized retinas resembling the persistence of fetal vasculature, along with underdeveloped pupils and a diminished red reflex. In twin II, the posterior chamber, lens and retina could not be visualized in either eye because the pupillary aperture was absent and subsequently, no red reflex was obtained. Intraocular pressure was normal in both twins.

Ocular ultrasonography in both twins revealed vitreous opacity, consistent with hemorrhage linked to aberrant coagulation. No mass or calcification was found, and retinal detachment was not detected.

Brain MRI of both twins showed bilateral microphthalmia, with abnormal dysmorphia affecting the anterior chambers of both orbits, and heterogeneous signal intensity indicating hemorrhage. The optic nerves were hypoplastic, with a small optic chiasm (fig. 3). No obvious extraconal fatty changes were observed. The appearance of the extraocular muscles was unremarkable.

Congenital defects were observed in both twins, including deep-seated eyes and coarse facial features. No chromosomal abnormalities were detected in a genomic study, but in both twins, molecular genetic analysis of the gene encoding vitamin K-dependent protein $\mathrm{C}$ (PROC) revealed a homozygous single-nucleotide substitution $(\mathrm{C}>\mathrm{T})$ at position 1,163 in exon 9 of the gene sequence (accession number: CM930622). This mutation resulted in the expression of defective protein $\mathrm{C}$, leading to thrombophilia. Functional assay revealed that serum protein $\mathrm{C}$ activity was $<1 \%$ of normal. This loss-of-function defect manifested, in both twins, as multiple attacks of disseminated intravascular coagulopathy, with purpuric skin lesions and intraocular bleeding. In twin II, bilateral inguinal hernia and cryptorchidism were also noticed. 


\section{Case Reports in Ophthalmology}

\begin{tabular}{l|l}
\hline DOI: $10.1159 / 000450571$ & (C) 2016 The Author(s). Published by S. Karger AG, Basel
\end{tabular} www.karger.com/cop

Almarzouki et al.: Peters Anomaly in Twins: A Case Report of a Rare Incident with Novel Comorbidities

\section{Discussion}

The exact etiology of Peters anomaly has been debated for many years. In a review paper published in 2011, Bhandari and colleagues [4] concluded that Peters anomaly is a condition of a sporadic incidence. However, autosomal dominant and autosomal recessive patterns of transmission have been reported in multiple families [7]. A number of chromosomal abnormalities and specific genetic mutations have been associated with Peters anomaly as well [8-10]. In a recent article, Takamiya et al. [11] concluded that human PAX6 mutations are linked to some ocular diseases, one of which was Peters anomaly. In addition, genetic mutations in beta 1,3-galactosyltransferase-like gene (B3GALTL) were proposed to cause Peters plus syndrome [12], while microdeletions of 8q21.11 have demonstrated variable manifestations of Peters anomaly [13].

Homozygous PROC mutation, causing protein C deficiency, was discovered in both of our patients, and is an extremely rare cause of hereditary thrombophilia, with an estimated worldwide incidence of 1 in 4,000,000 live births [14]. Although many disorders have been observed in patients with Peters anomaly, the association with homozygous PROC mutation has not been reported previously.

Diverse ocular conditions have been associated with Peters anomaly, most commonly glaucoma, microphthalmia and coloboma [15]. Although glaucoma is common in patients with Peters anomaly, it was absent in our patients. By contrast, there are some rare manifestations reported only in individual cases such as corneal perforation [6]. Our patients had a number of conditions that have not previously been reported in association with Peters anomaly, specifically, hypoplasia of the optic nerves and optic chiasm, as well as, in one of the twins, bilateral complete absence of the pupillary aperture.

A number of systemic conditions have been reported in association with Peters anomaly [4]. Currently available data suggest that bilateral presentation of Peters anomaly has a stronger association with systemic findings than unilateral presentation [4]. Cleft lip and cleft palate, cardiac anomalies, gastrointestinal malformations, cryptorchidism and inguinal hernia have all been reported to be associated with Peters anomaly [4]. In agreement with these results, both cryptorchidism and bilateral inguinal hernia were present in one of our patients.

\section{Conclusion}

The novel presentation of Peters anomaly in monozygotic twins sharing a mutation in PROC gene provides further evidence for the existence of a genetic basis to this condition. Hypoplasia of the optic nerves and optic chiasm, along with severe protein C deficiency and bilateral absence or underdevelopment of the pupils, are all associated pathologies that have not previously been reported.

When a diagnosis of Peters anomaly is made, a thorough search for associated ocular and systemic conditions should be conducted. As more of these pathologies are identified, our understanding of this enigmatic condition will increase. 
Almarzouki et al.: Peters Anomaly in Twins: A Case Report of a Rare Incident with Novel Comorbidities

\section{Acknowledgement}

The authors of this study express their sincere gratitude to the family of the patients for their cooperation and willingness to participate.

\section{Statement of Ethics}

Parental informed consent to participate in this study was obtained after discussing the possibility of publication.

\section{Disclosure Statement}

The authors declare that they have no conflicts of interest.

\section{References}

1 Peters A: Über angeborene Defektbildung der Descemetschen Membran. Klin Monbl Augenheilkd 1906;44:27-40.

-2 Townsend W, Font RL, Zimmerman L: Congenital corneal leukoma. Histopathological findings in 19 eyes with central corneal defects in Descemet's membrane. Am J Ophthalmol 1974;77:192.

-3 Zaidman GW, Flanigan JK, Furey CC: Long-term visual prognosis in children after corneal transplant surgery for Peters anomaly type I. Am J Ophthalmol 2007;144:104-108.

4 Bhandari R, Ferri S, Whittaker B, et al: Peters anomaly: review of the literature. Cornea 2011;30:939944.

5 Myles WM, Flanders ME, Chitayat D, et al: Peters' anomaly: a clinicopathologic study. J Pediatr Ophthalmol Strabismus 1992;29:374-381.

-6 Eiferman RA: Association of Wilms' tumor with Peter's anomaly. Ann Ophthalmol 1984;16:933-934.

7 Frydman M, Weinstock AL, Cohen HA, et al: Autosomal recessive Peters anomaly, typical facial appearance, failure to thrive, hydrocephalus, and other anomalies: further delineation of the KrauseKivlin syndrome. Am J Med Genet 1991;40:34-40.

8 Dahl E, Koseki H, Balling R: Pax genes and organogenesis. Ophthalmic Surg Lasers 1997;28:311-312.

-9 Doward W, Perveen R, Lloyd IC, et al: A mutation in REIG1 gene associated with Peters' anomaly. J Med Genet 1999;36:152-155.

10 Iseru SU, Osbourne RJ, Farrall M, et al: Seeing clearly: the dominant and recessive nature of FOXE3 in eye developmental anomalies. Hum Mutat 2009;10:1378-1386.

11 Takamiya M, Weger BD, Schindler S, et al. Molecular description of eye defects in the zebrafish Pax6b mutant, sunrise, reveals a Pax6b-dependent genetic network in the developing anterior chamber. PLoS One 2015;10:e0117645.

$\$ 12$ De nie KF, Wesseling P, Eggink CA: Unique presentation of corneal opacity in Peters plus syndrome: an unusual form of Peters anomaly showing tissue repair in serial analysis. Cornea 2016;35:277-280.

-13 Happ H, Schilter KF, Weh E, Reis LM, Semina EV: 8q21.11 microdeletion in two patients with syndromic Peters anomaly. Am J Med Genet A 2016;170:2471-2475.

14 Goldenberg NA, Manco-Johnson MJ: Protein C deficiency. Haemophilia 2008;14:1214-1221.

-15 Najjar DM, Christiansen SP, Bothun ED, et al: Strabismus and amblyopia in bilateral Peters anomaly. JAAPOS 2006;10:193-197. 


\section{Case Reports in Ophthalmology}

\begin{tabular}{l|l}
\hline Case Rep Ophthalmol 2016;7:186-192 \\
\hline DOI: 10.1159/000450571 & $\begin{array}{l}\text { C 2016 The Author(s). Published by S. Karger AG, Basel } \\
\text { www.karger.com/cop }\end{array}$ \\
\hline
\end{tabular}

Almarzouki et al.: Peters Anomaly in Twins: A Case Report of a Rare Incident with Novel Comorbidities

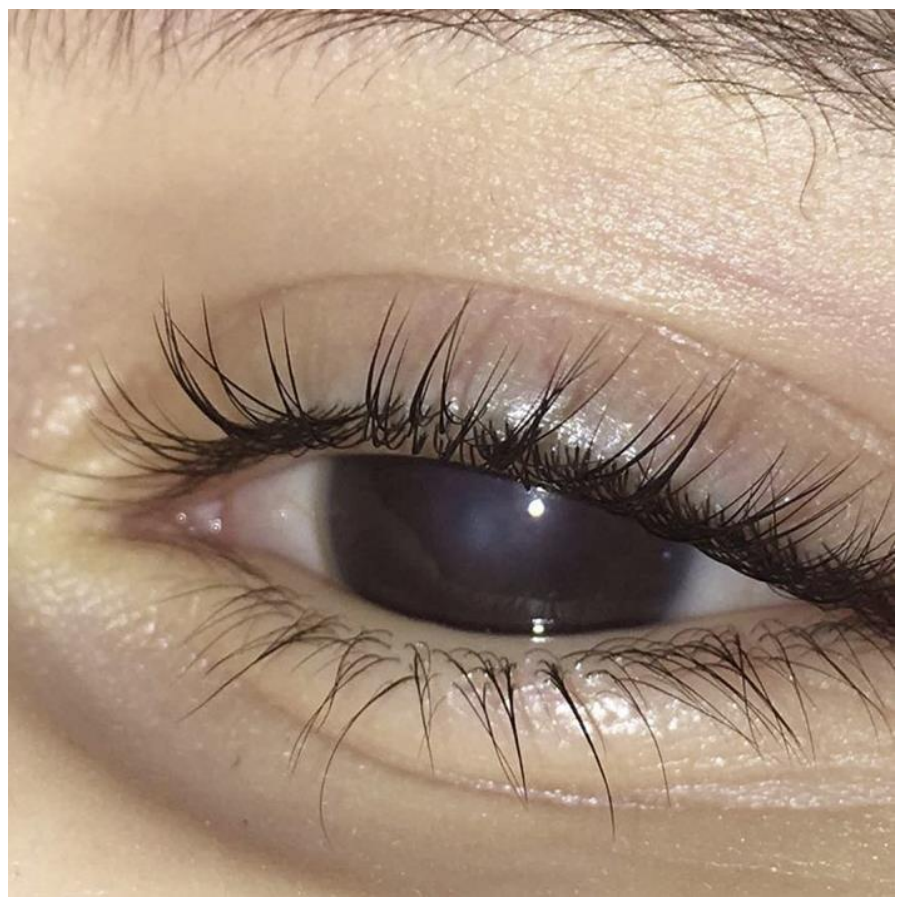

Fig. 1. Photograph of the gross anatomy of the left eye of twin I, showing central corneal opacity.

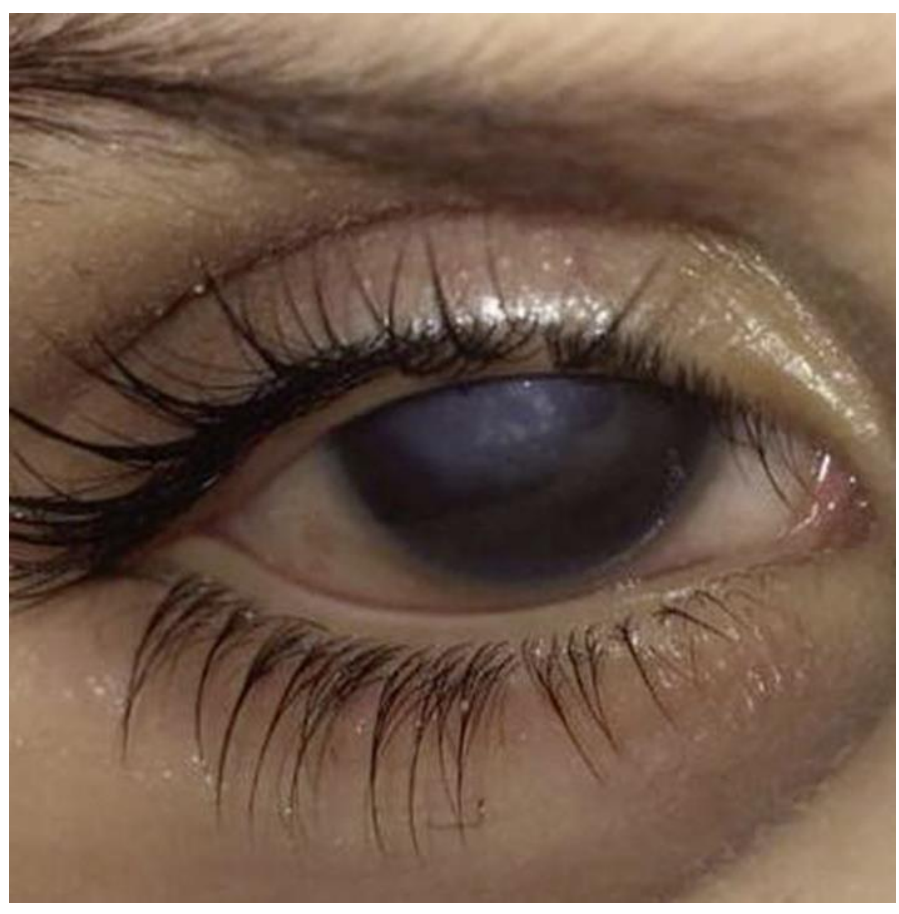

Fig. 2. Photograph of the gross anatomy of the right eye of twin II, showing prominent central corneal opacity. 
Case Reports in
Ophthalmology

Case Rep Ophthalmol 2016;7:186-192

DOI: $10.1159 / 000450571$

(C) 2016 The Author(s). Published by S. Karger AG, Basel www.karger.com/cop

Almarzouki et al.: Peters Anomaly in Twins: A Case Report of a Rare Incident with Novel Comorbidities

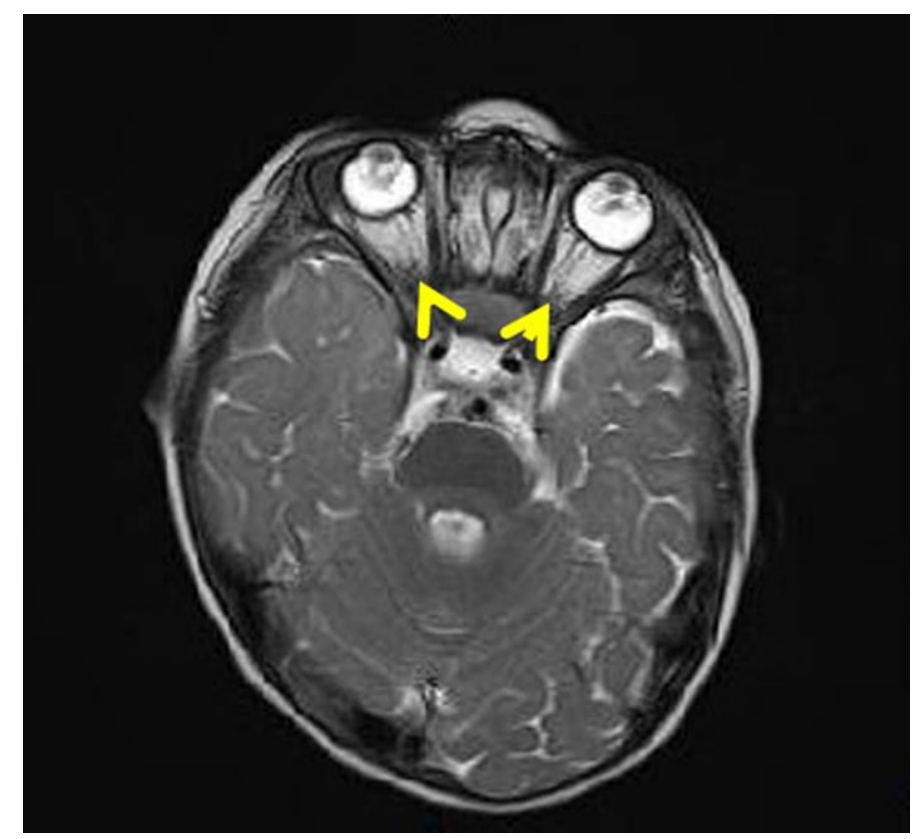

Fig. 3. T2-weighted MRI brain scan of twin II, showing bilateral microphthalmia with abnormal dysmorphic changes in the anterior chamber. Bilateral hypoplastic changes of the optic nerve were noted (arrowheads), along with a small optic chiasm. Similar abnormalities were observed in twin I. 